\title{
El procedimiento administrativo sancionador en materia de tráfico, circulación de vehículos a motor y seguridad vial: El debido equilibrio entre especialidades y garantías
}

\author{
Vicenç Aguado i Cudolà \\ Profeso titular Derecho Administrativo, Acreditado Catedrático \\ Universidad de Barcelona
}

\begin{abstract}
Resumen
Las características propias de las sanciones de tráfico, especialmente su carácter masivo y su carácter fugaz e instantáneo, justifican la adopción de determinadas especialidades procedimentales, como pueden ser la terminación anticipada del procedimiento a través de la reducción de la cuantía de la sanción y determinadas medidas destinadas a agilizar el procedimiento o administrativo y la ejemplaridad de las sanciones que puedan imponerse. La Ley 18/2009, de 23 de noviembre, ha introducido novedades significativas en el procedimiento sancionador de tráfico, en búsqueda de una mayor simplificación administrativa y de una mayor eficacia de la Administración, así como ha subrayado el carácter supletorio de la Ley 30/1992, de 26 de noviembre, respecto a estos procedimientos. En cualquier caso, las especialidades procedimentales sancionadoras en materia de tráfico no deberían suponer, sin embargo, una disminución o limitación de las garantías comunes de los ciudadanos ante las Administraciones públicas, sino que debe irse a un equilibrio que compatibilice las especialidades con las garantías.
\end{abstract}

Palabras clave Procedimiento administrativo sancionador, Administración sancionadora, Tráfico, Circulación, Seguridad vial, Simplificación administrativa, Garantías comunes de los ciudadanos ante las Administraciones, Especialidades procedimentales.

\section{The administrative sanctioning procedure on traffic, traffic of vehicles to engine and road safety matters : The due balance between specialities and common guarantees}

\begin{abstract}
The own characteristics of the sanctions of traffic, specially its massive character and his fleeting and instantaneous character, justify the adoption of certain procedural specialities, since they can be the early completion of the procedure across the reduction of the quantity of the sanction and determined measures destined to improve the procedure or administrative officer and the exemplary nature of the sanctions that could be imposed. The Law 18/2009, of November 23, has introduced significant innovations in the sanctioning procedure of traffic, in search of a major administrative simplification and of a major efficiency of the Administration, as well as the supplementary character of the Law has underlined 30/1992, of November 26, with regard to these procedures. In any case, the procedural sanctioning specialities as for traffic should not suppose, nevertheless, a decrease or limitation of the common guarantees of the citizens before the public Administrations, but it must go away to a balance that makes compatible the specialities with the guarantees.
\end{abstract}

Key words

Administrative sanctioning procedure, Sanctioning Administration, Traffic, Road Security, Common guarantees of the citizens before the Administrations, Procedural specialities. 


\section{LAS ESPECIALIDADES DEL PROCEDIMIENTO ADMINISTRATIVO SANCIONADOR EN MATERIA DE TRÁFICO, CIRCULACIÓN DE VEHÍCULOS A MOTOR Y SEGURIDAD VIAL: SU JUSTIFICACIÓN}

Entre los méritos que se destacaron de la Ley de Procedimiento Administrativo de 17 de julio de 1958 (LPA) fue la superación de la departamentalización de procedimientos administrativos provocada por la Ley Azcárate en 1889. La LPA estableció un procedimiento general y tres procedimientos especiales: el de elaboración de disposiciones reglamentarias, el sancionador y el de reclamaciones previas al ejercicio de acciones civiles y laborales. Este modelo idealizado debía complementarse, en la práctica, con la regulación específica que en materia de procedimiento administrativo introducía la legislación sectorial. Regulación sectorial que no solamente se limitaba a establecer los órganos competentes para iniciar, incoar y resolver el procedimiento, sino que se refería a trámites fundamentales del procedimiento como, por ejemplo, las medidas provisionales ${ }^{1}$ o la terminación ${ }^{2}$.

Con una lucidez y anticipación extraordinaria, el legislador de 1958 articuló un procedimiento administrativo sancionador que se establecía como una garantía, al mismo tiempo que se estructuraba a través de la separación entre las fases de instrucción y de resolución. Dos décadas más tarde, el reconocimiento de las garantías procesales del art. 24 de la Constitución ${ }^{3}$ a los procedimientos administrativos sancionadores fue acentuando la singularidad de estos procedimientos respecto al resto de procedimientos administrativos. La “procesalización" del procedimiento administrativo sancionador ha comportado la existencia de una consolidada doctrina elaborada por la jurisprudencia del Tribunal Constitucional y del Tribunal Supremo.

1 Era frecuente, como lo es en la actualidad, la regulación a través de la legislación sectorial de las medidas provisionales del procedimiento. Con ello se concretaba las medidas que se preveían con carácter general, el art. 72 de la LPA y en la actualidad el art. 72 de la LRJPAC; al mismo tiempo que se preveía si éstas podían o no adoptarse con carácter previo a la iniciación formal del procedimiento administrativo. Vid. M. Rebollo Puig: "Medidas provisionales en el procedimiento administrativo” en AA.VV.: La protección jurídica del ciudadano: (procedimiento administrativo y garantía jurisdiccional): Estudios en homenaje al profesor Jesús González Pérez, vol. 1 (Consideraciones generales: el procedimiento administrativo), Ed. Civitas, Madrid, 1993, pp. 659-710.

2 Así, por ejemplo, la caducidad del procedimiento por causa imputable a la Administración únicamente regía en aquellos ámbitos materiales donde la legislación sectorial la había reconocido expresamente. Esta doctrina del Tribunal Supremo se apoyaba en que el art. 49 de la LPA (actual art. 63.3 de la LRJPAC) según el cual: "Las actuaciones administrativas realizadas fuera del tiempo establecido solo implicarán la anulación del acto, si así lo impusiera la naturaleza del término o plazo y la responsabilidad del funcionario de la demora si a ello hubiere lugar". Afortunadamente, esta doctrina fue superada por el art. 44.2 de la LRJPAC. Por todos, vid. V. Aguado i Cudolà: Prescripción y caducidad en el ejercicio de potestades administrativas, Ed. Marcial Pons, Madrid-Barcelona, 1999.

3 Este reconocimiento se produjo a través de la STC 18/1981, de 8 de junio, según la cual: "los principios inspiradores del orden penal son de aplicación, con ciertos matices, al derecho administrativo sancionador, dado que ambos son manifestaciones del ordenamiento punitivo del Estado", añadiéndose que: "los principios esenciales reflejados en el art. 24 de la Constitución en materia de procedimiento han de ser aplicables a la actividad sancionadora de la Administración, en la medida necesaria para preservar los valores esenciales que se encuentran en la base del precepto [...] con el alcance que requiere la finalidad que justifica la previsión constitucional". 
La vigente Ley 30/1992, de 26 de noviembre, de régimen jurídico de las administraciones públicas y del procedimiento administrativo común (en adelante LRJPAC) también realizó un tratamiento específico del procedimiento administrativo sancionador. Esta Ley estableció en un título (el IX) y un capítulo (el segundo) "los principios del procedimiento administrativo sancionador”. No se trata, por tanto, de la regulación de un procedimiento sancionador sino que se establecen una serie de derechos y reglas que deben respetarse en su regulación. Con esta regulación de menor densidad normativa se facilitaba que las Comunidades Autónomas pudieran fijar sus propias reglas procedimentales en el caso que tuvieran competencias exclusivas o concurrentes sobre la materia. En el caso de la materia de tráfico, circulación de vehículos a motor y seguridad vial nos encontramos ante una competencia exclusiva del Estado (art. 149.1.21 de la CE) que en determinadas Comunidades Autónomas se ha convertido en compartida, al ser transferidas las facultades de ejecución por la vía de la ley orgánica del art. 150.2 de la $\mathrm{CE}^{4}$. En cualquier caso, las CCAA no tienen competencias legislativas esta materia por lo que la regulación de su procedimiento administrativo sancionador continúa en manos del Estado.

Por tanto, la LRJPAC al regular el procedimiento administrativo sancionador no establece, a diferencia de la LPA, una serie de trámites, formalizados o no, sino una serie de reglas que deben respetar en todo caso las correspondientes normas de procedimiento. La función principal de estas reglas es la de dar cobertura normativa a la regulación del procedimiento administrativo sancionador que, con carácter general, se encuentra en el RD 1398/1993, de 4 de agosto, al mismo tiempo que establecer unos derechos de los presuntos responsables de las infracciones administrativas. Con ello se viene a cumplir la reserva de ley que el art. 105.c) de la CE cuando se establece que la ley regulará: "El procedimiento a través del cual deben producirse los actos administrativos, garantizando, cuando proceda, la audiencia del interesado".

En el ámbito específico del tráfico, circulación de vehículos a motor y seguridad vial, el Estado ha ejercido sus competencias legislativas a través del Texto Articulado de la Ley, aprobado por RD Legislativo 339/1990, de 2 de marzo (en adelante Texto Articulado de la Ley de Tráfico). Este texto fue desarrollado en la materia que ahora nos interesa por el Reglamento de procedimiento sancionador en materia de tráfico, circulación de vehículos a motor y seguridad vial, aprobado por Real Decreto 320/1994, de 25 de febrero. Pese a su nombre este Reglamento no regula un procedimiento administrativo sancionador, sino las especialidades que se centran fundamentalmente en

4 La asunción de competencias ejecutivas en materia de tráfico se realizó en Catalunya, a través de la Ley Orgánica 6/1997, de 15 de diciembre, de Transferencia de Competencias Ejecutivas en Materia de Tráfico y Circulación de vehículos a Motor a la Comunidad Autónoma de Catalunya. Dichas competencias sobre "el control y la vigilancia del tráfico" también han sido recogidas en el art. 164.1.c) del Estatut de Catalunya de 2006. En el caso de Euskadi, dicho proceso se realizó directamente a través de normas reglamentarias que se apoyaban directamente en las previsiones genéricas que realizaba el Estatuto de Guernika sobre la policía autonómica Ertzaintza, que no hablan de seguridad vial, ni de tráfico y circulación de vehículos a motor, sin la cobertura de una ley orgánica de transferencia del art. 150.2 de la CE. En concreto, a través del Real Decreto 3256/1982, de 15 de octubre, sobre traspaso de servicios del estado a la Comunidad Autónoma del País Vasco en materia de ejecución de la legislación del Estado sobre tráfico y circulación de vehículos. 
las denuncias, notificaciones, pago anticipado de la sanción, prueba y presunción de certeza o veracidad, caducidad y procedimiento ejecutivo.

En la regulación reglamentaria de procedimientos administrativos se ha apuntado la necesidad de limitarla a los tipos de actuación administrativa con independencia del sector de que se trate. Así habría un procedimiento administrativo sancionador, de subvenciones, de autorizaciones, de responsabilidad patrimonial de la Administración, etc, en vez de un procedimiento por cada tipo de ámbito material lo que daría lugar a una departamentalización similar a la que produjo en su momento la Ley Azcárate. Esta visión comportaría la necesidad de evitar, salvo excepciones debidamente justificadas, la regulación de procedimientos administrativos especiales según el ámbito material de que se trate.

La singularidad de los procedimientos administrativos respecto a la LRJPAC se ha producido en diversos ámbitos materiales: a) tributario (Disposición Adicional $5^{2}$ de la LRJPAC); b) actos de seguridad social y desempleo (Disposición Adicional $6^{\text {a }}$ de la LRJPAC); c) procedimiento administrativo sancionador por infracciones en el orden social y para la extensión de actas de liquidación de cuotas de la Seguridad Social (Disposición Adicional $7^{\text {a }}$ de la LRJPAC); d) procedimientos disciplinarios (Disposición Adicional $8^{\mathrm{a}}$ de la LRJPAC); e) procedimientos administrativos instados ante misiones diplomáticas y oficinas consulares (Disposición Adicional $11^{\text {a }}$ de la LRJPAC).

La Ley 18/2009, de 23 de noviembre, ha añadido a estos procedimientos el sancionador en materia de tráfico y seguridad vial (Disposición Adicional $8^{\text {a }}$ bis de la LRJPAC). Por tanto, estos procedimientos se regirán por lo dispuesto en su legislación específica y, supletoriamente, por lo dispuesto en la LRJPAC. En el Preámbulo de la Ley 18/2009 se ha puesto de relieve una serie de razones que, a juicio del legislador, singularizarían los procedimientos administrativos sancionadores en materia de tráfico y seguridad vial:

"La experiencia acumulada durante los últimos años pone de manifiesto, además, la necesidad de construir un procedimiento especial para el ámbito sancionador del tráfico donde puedan ser tenidas en cuenta las especialidades que lo diferencian de los demás procedimientos administrativos.

En primer lugar, su carácter masivo. Treinta millones de vehículos y veinticinco millones de conductores arrojan en nuestras calles y carreteras más de quince millones de procedimientos sancionadores por infracciones a la normativa de circulación. Una cifra que, antojándose espectacular, dista sin embargo mucho de la existente en el resto de países europeos de nuestro entorno donde los sistemas automáticos de detección de infracciones llegan a multiplicar por diez el número existente en nuestro país.

En segundo lugar, el carácter mismo de la infracción de tráfico. La veracidad de los hechos otorgada por los medios técnicos homologados o por los Agentes de la Autoridad dejan poco margen a la duda. 
La diversidad de Administraciones con competencias sancionadoras en materia de tráfico es una característica que también debe ser tenida en cuenta. La Ley unifica criterios en la idea de que el conductor tenga siempre presente que su comportamiento contrario a la norma, con independencia del lugar en que se cometa la infracción y de la Administración competente, va a recibir el mismo reproche jurídico.

Finalmente, con presencia probablemente en cada uno de los preceptos, late la voluntad de profundizar en la idea de la sanción de tráfico como un elemento de seguridad preventiva en la conducción: se trata de evitar la producción de los accidentes ocasionados por un comportamiento infractor. Diferentes experiencias adoptadas en países de nuestro entorno dejan claro que una adecuada gestión del procedimiento sancionador influye de un modo directo en la reducción de la siniestralidad."

El principal argumento para justificar la especialidad de las sanciones de tráfico es probablemente el carácter masivo con que se cometen estas infracciones. Este mismo argumento se ha utilizado en otro tipo de procedimientos como los tributarios o los de extranjería 5 . Ahora bien, ¿qué tipo de especialidades pueden justificarse en base al carácter masivo de las infracciones? La especialidad podría quedar reflejada en aspectos tales como la práctica de notificaciones, así como mediante la incorporación de medios automatizados que permitan ahorrar tiempo y coste respecto a la tramitación de trámites sustancialmente idénticos para un gran número de personas. Ello, sin embargo, no debería comportar una merma de las garantías de los ciudadanos. Se requerirá, por tanto, que en las actuaciones administrativas se establezcan las circunstancias específicas de cada caso, sin que sean sustituidas por fórmulas estereotipadas. Esta cuestión se ha planteado directamente en un recurso de casación en interés de ley que el Tribunal Supremo (Sala de lo Contencioso-Administrativo, Sección $4^{\mathrm{a}}$ ) resolvió en Sentencia de 15 noviembre 2000 (RJ 2000|10065). En este caso el Ayuntamiento de Madrid consideraba como gravemente dañosa para el interés general la doctrina en base a la cual se había anulado por falta de suficiente motivación la resolución mediante un acto de una pluralidad de procedimientos sanciona-

5 En el caso de la extranjería la especialidad ha llevado a justificar la limitación de la motivación de la denegación de visados a unos supuestos determinados. Vid. V. Aguado i Cudolà: “Libertades de circulación y residencia: el visado como control de entrada de extranjeros" en Revista Aragonesa de Administración Pública, N. ${ }^{\circ}$ Extra 6, 2003 (Ejemplar dedicado a: Ciudadanía e inmigración / coord. por Francisco Velasco Caballero, Luis Alberto Pomed Sánchez), pp. 259-300. En la actualidad con la reforma de la Ley Orgánica 4/2000, de 11 de enero, de derechos y libertades de los extranjeros en España y su integración social por la Ley Orgánica 2/2009, de 11 de diciembre, se establece que: "La denegación de visado deberá ser motivada cuando se trate de visados de residencia para reagrupación familiar o para el trabajo por cuenta ajena, así como en el caso de visados de estancia o de tránsito. Si la denegación se debe a que el solicitante del visado está incluido en la lista de personas no admisibles prevista en el Convenio de aplicación del Acuerdo de Schengen de 14 de junio de 1990, se le comunicará así de conformidad con las normas establecidas por dicho Convenio. La resolución expresará los recursos que contra la misma procedan, órgano ante el que hubieran de presentarse y plazo para interponerlos." Otra de las especialidades de los procedimientos de otorgamientos de visados es la obligación de comparecencia personal que puede comportar la inadmisión de la solicitud. Vid. al respecto V. Aguado i Cudolà: "Las causas de inadmisibilidad en los procedimientos administrativos en materia de extranjería: los problemas de inconstitucionalidad de la disposición adicional cuarta de la Ley Orgánica 14/2003, de 20 de noviembre" en Revista de derecho migratorio y extranjería.5, 2004, pp. 123-139. 
dores en materia de tráfico, que se justificaban únicamente en la inexistencia de alegaciones contra las denuncias debidamente notificadas, al haber servido las mismas de propuesta de resolución. El TS desestima el recurso al considerar que: "La motivación de la imposición de una sanción no puede referirse únicamente a la inexistencia de alegaciones de descargo en el expediente, sino a la apreciación de la realidad de la infracción, de su correcta tipificación y graduación, así como de la ausencia de circunstancias exonerantes, siquiera por concurrencia de la prescripción de la acción o de la caducidad del procedimiento. La necesaria especificación de las circunstancias que individualizan la imposición de la sanciones es requisito ineludible en un procedimiento de este tipo, requisito cuya necesidad ha de valorarse caso por caso, pero que no puede ser suplido por la ausencia de alegaciones de descargo como razón única que justifica la imposición de la sanción en los casi dos mil expedientes examinados." La ausencia de alegaciones puede comportar una agilización del procedimiento, como vernos, pero, en cambio, no puede substituir la necesaria motivación que requiere cualquier resolución administrativa sancionadora en la que, en cualquier caso, se debe valorar las pruebas existentes y la procedencia o no de la sanción.

Se utiliza también como argumento para justificar la especialidad de las infracciones de tráfico, el hecho que las pruebas dejan poco margen de duda, invocándose tanto la presunción de certeza de las denuncias como los medios técnicos utilizados para la detección y prueba de determinadas infracciones, por ejemplo los cinemómetros o los controladores del exceso de velocidad. El hecho de que estas infracciones se constaten a través de medios de prueba muy fiables no constituye, por sí mismo, un argumento definitivo. Este mismo tipo de justificación era la que se utilizaba para fundamentar las denominadas sanciones de plano, que se imponían sin dar audiencia a la persona imputada en el procedimiento ${ }^{6}$. Así, se señalaba que al ser irrebatible los hechos constitutivos de la infracción era irrelevante el abrir un trámite de alegaciones o de prueba.

A mi modo de ver, lo que realmente singularizaría no es tanto el medio de prueba, sino las características propias de la infracción. Se trata de infracciones que pueden tener una duración muy limitada en el tiempo, como pueden ser las de carácter instantáneo.

Pensemos en el caso de un vehículo que se salta una señal de stop o un semáforo en rojo. La especialidad procedimental que se justificaría en este caso es la posibilidad de que el presunto infractor pueda acogerse a la finalización anticipada del procedimiento y a cambio de ello se beneficie de una reducción en el importe de la sanción que vendría a ser una compensación por los gastos que comporta a la Admi-

6 Las "sanciones de plano" se fundamentaban en tres criterios: urgencia, ejemplaridad y hecho patente, según explica L. Martín Retortillo Baquer: Las sanciones de orden público en el Derecho español I, Ed. Tecnos, Madrid, pp. 233 y ss. Según establecía, el art. 137.2 del Reglamento de procedimiento administrativo del Ministerio de Gobernación, aprobado por Decreto de 31 de enero de 1947: "La Autoridad correspondiente podrá acordar, mediante proveído y bajo su responsabilidad: $5^{\text {a }}$ La sanción de plano, cuando de 66 la denuncia o antecedentes apareciere comprobada la infracción o extralimitación y además no exista precepto legal aplicable que exija la incoación de expediente [ ].” 
nistración la tramitación del procedimiento sancionador. Ello no significa necesariamente el reconocimiento de la responsabilidad a cambio de una rebaja en la sanción, por cuanto tal condicionamiento sería inconstitucional al ser contrario al derecho a no confesarse culpable. Lo único que supone es renunciar a la vía administrativa, dejando a salvo la vía contencioso-administrativa. En la práctica, sin embargo, el denunciado que se acoge a esta posibilidad difícilmente irá a un contencioso-administrativo a gastarse en abogado y, en su caso procurador, lo que se ha ahorrado en vía de recurso, a menos que además de los efectos económicos de la sanción se produzca la retirada del permiso de conducir por habérsele agotado los puntos disponibles.

La diversidad de administraciones con competencias sancionadoras requiere la necesidad de determinar con claridad los criterios para determinar cuáles son las responsabilidades de cada una, también puede requerir la utilización de técnicas de colaboración y coordinación interadministrativa. En esta línea, se prevé la posibilidad de que "los órganos de las diferentes administraciones públicas podrán delegar el ejercicio de sus competencias sancionadoras mediante convenios o encomiendas de gestión o a través de cualesquiera otros instrumentos de colaboración previstos en la legislación de procedimiento administrativo común" (art. 71.2 del Texto Articulado). La diversidad de administraciones (Administración del Estado, algunas Comunidades Autónomas y los Municipios) comporta, por tanto, determinar con claridad las competencias y establecer pautas para una actuación eficaz y coordinada.

Finalmente, hay que mencionar la finalidad última que el ordenamiento jurídico atribuye a las sanciones de tráfico, esto es la finalidad preventiva de evitar accidentes de circulación. Para conseguir esta finalidad la legislación busca una ejemplaridad inmediata. En este sentido, cobra una relevancia significativa la ejecutividad de las sanciones administrativas. De acuerdo con la legislación general, las sanciones administrativas son ejecutivas cuando ponen fin a la vía administrativa (art. 138.3 de la LRJPAC). Para conseguir esta ejecutividad inmediata las sanciones en materia de tráfico ponen fin a la vía administrativa (81.5 del Texto Articulado de la Ley de Tráfico). Esta previsión si bien es coherente con la LRJPAC puede plantear, sin embargo, problemas desde el punto de vista del derecho a la tutela judicial efectiva. Como parte de derecho fundamental, la jurisprudencia constitucional ha incluido la tutela cautelar, por cuanto de otra forma la ejecutividad inmediata de las sanciones podría llegar a condicionar en algunos casos la efectividad de la sentencia judicial, tal y como veremos más adelante.

\section{LA FUNCIONALIDAD DE LOS TRÁMITES EN EL PROCEDIMIENTO ADMINISTRATIVO SANCIONADOR}

\section{Garantizar la imparcialidad: La debida separación entre fase de instrucción y fase de resolución}

Por mandato constitucional (art. 103.3 de la CE), la ley regulará las garantías para la imparcialidad en el ejercicio de las funciones de los funcionarios públicos. Entre estas garantías, la LRJPAC prevé unas causas de abstención (art. 28) que obligan a abste- 
nerse al funcionario público o, en caso, de que éste no lo haga, se faculta a la persona interesada a ejercer la recusación (art. 29). Para poder ejercer, en su caso, la recusación, la LRJPAC reconoce, entre los derechos del presunto responsable, el de que se le notifique la identidad del instructor, de la autoridad competente para imponer la sanción y de la norma que atribuya tal competencia. En el caso de las infracciones de tráfico y seguridad vial, en las denuncias formuladas por los agentes de la autoridad deberá constar su número de identificación personal [art. 74.2.d) del Texto Articulado de la Ley de Tráfico] y el órgano competente para imponer la sanción y la norma que le atribuye tal competencia [art. 74.3.b) del Texto Articulado de la Ley de Tráfico]. Esta identificación, aunque no sea completa, también es relevante para determinar si el Agente de la Autoridad estaba en la situación de constatar la infracción administrativa, así como si podía practicar o no en ese momento la notificación de la denuncia7.

Para garantizar una adecuada imparcialidad se ha insistido en la necesidad de que las fases de instrucción y resolución se articulen de forma separada, atribuyéndose a órganos distintos. Tal consideración trae su fundamento en el hecho que el instructor del procedimiento, al verse directamente implicado en la tarea de recabar informaciones y pruebas necesarias para determinar con precisión los hechos acontecidos, puede verse "contaminado" al realizar esta función, por lo que su imparcialidad puede quedar en entredicho. Por ello, en el ámbito del Derecho penal, la jurisprudencia constitucional (STC 145/1988, de 12 de julio) declaró que la separación entre juez instructor y sentenciador formaba parte del contenido esencial del derecho fundamental al juez imparcial predeterminado (art. 24.2 de la CE).

La aplicación con ciertos matices de las garantías del art. 24.2 de la CE al procedimiento administrativo sancionador podría llevar a pensar en la extensión al mismo del derecho al juez imparcial predeterminado sancionador. Sin embargo, la jurisprudencia constitucional excluyó esta garantía de los procedimientos administrativos sancionadores al considerar que se trataba de una garantía propia del ámbito judicial no trasladable sin más al ejercicio del ius puniendi por la Administración pública (STC 22/1990, de 15 de febrero). No obstante, el art. 134.2 de la LRJPAC establece que los procedimientos que regulen el ejercicio de la potestad sancionadora han de establecer la separación necesaria entre la fase instructora y la sancionadora, y las han de encomendar a órganos diferentes. Se trata, por tanto, de una garantía establecida por el legislador y que no tiene, sin embargo, relevancia constitucional.

7 Vid. la STSJ País Vasco (Sala de lo Contencioso-Administrativo, Sección $3^{\text {a }}$ ) núm. 848/2000 de 5 octubre (RJCA 2001|195): “No siendo necesaria la identificación completa del agente denunciante, a tenor de lo establecido en el artículo 5 del Real Decreto 320/1994, de 25 de febrero (lo que determinaría la impertinencia de la prueba propuesta “de necesaria declaración por el instructor”), sí resulta pertinente la aportación al procedimiento sancionador del "parte del día” (Orden de servicio) que les encomendaba la vigilancia del punto kilométrico donde fue denunciado el recurrente en tanto que no sólo sirve para acreditar la regularidad y aleatoriedad de la denuncia formulada sino también el número de agentes que componían la patrulla, de indudable importancia para acreditar otro de los motivos impugnatorios formulados por el recurrente como es la falta de parada y notificación del acto de la denuncia formulada. En este sentido, también era pertinente la aportación del informe de los agentes denunciantes a fin de que explicasen las causas concretas de no notificar en el acto la denuncia al recurrente." 
Esta garantía legal no implica que los órganos instructores y sancionadores deban tener una independencia jerárquica, sino que pueden tratarse de unidades administrativas que forman parte de un órgano administrativo complejo. Así, lo reconoce la Exposición de Motivos del Reglamento de procedimiento administrativo sancionador, aprobado por RD 1398/1993, de 4 de agosto, cuando señala que:

“La innovadora recepción que efectúa la LRJ-PAC del principio del orden penal de la separación entre órgano instructor y órgano que resuelve ha de entenderse, como es evidente y ha sido declarado por la jurisprudencia constitucional (sentencia de 8 de junio de 1981), de forma adecuada a la naturaleza administrativa. En el orden penal, el principio atiende a la configuración, en muchas ocasiones unipersonal, de los órganos judiciales y pretende, por tanto, que no sea la misma persona o personas las que acusen y resuelvan. En sede administrativa la traslación de tal principio requiere, para que constituya una verdadera garantía, que el concepto de órgano no sea asimilable al de órgano administrativo meramente organizativo y jerárquico que recogen algunas normas, sino que la capacidad de autoorganización que el artículo 11 de la LRJ-PAC reconoce a las Administraciones Públicas debe traducirse en el ámbito sancionador en una flexibilización al servicio de la objetividad. En consecuencia, el concepto de órgano que ejerce -iniciando, instruyendo o resolviendo- la potestad sancionadora resulta de la atribución de tales competencias a las unidades administrativas que, en el marco del procedimiento de ejercicio de la potestad sancionadora y a sus efectos, se constituyen en órganos, garantizándose que no concurran en el mismo las funciones de instrucción y resolución."

De acuerdo con esta interpretación el art. 10 del Reglamento de Procedimiento Sancionador señala que a "efectos de este Reglamento, son órganos administrativos competentes para la iniciación, instrucción y resolución de los procedimientos sancionadores las unidades administrativas a las que, de conformidad con los artículos 11 y 21 de la LRJ-PAC, cada Administración atribuya estas competencias, sin que puedan atribuirse al mismo órgano para las fases de instrucción y resolución del procedimiento." Esta interpretación que ha sido criticada por un relevante sector de la doctrina al considerar que el Reglamento viene a desvirtuar el mandato establecido por el legislador ${ }^{8}$. Sin lugar a dudas, esta interpretación responde a criterios de eficacia y a la propia estructura

8 Según E. García de Enterría el Reglamento “se esfuerza en aguar” la regla de separación entre órganos de instrucción y de resolución "con una interpretación puramente formalista, invalidando así la idea esencial del artículo 134.2 de la Ley, que proviene de su formulación en las Sentencias constitucionales de 12 de julio de 1988, 12 de diciembre de 1991, 23 de septiembre y 13 de octubre de 1992, de que el instructor no dependa jerárquicamente de la autoridad sancionadora, pues en otro caso la separación de órganos carece de cualquier significado". Vid. de este autor “La problemática puesta en aplicación de la LRJ-PAC: el caso del Real Decreto 1398/1993, de 4 de agosto, que aprueba el Reglamento de procedimiento para el ejercicio de la potestad sancionadora: Nulidad radical del Reglamento y desintegración general del nuevo sisema legal" en Civitas. Revista española de derecho administrativo, 80, 1993, pp. 655-678. Debe advertirse, no obstante, que esta jurisprudencia ha recaído fundamentalmente en asuntos penales y no en administrativos sancionadores. Como se ha dicho anteriormente la jurisprudencia constitucional viene siendo reacia a extender la imparcialidad al procedimiento administrativo sancionador hasta sus últimas consecuencias como sucede en el proceso penal. 
organizativa de la Administración pública que no necesariamente debe estructurarse de forma similar a como acontece en el ámbito judicial. En cualquier caso, si bien existe dependencia jerárquica, si que existe un distanciamiento del órgano que resuelve sobre la instrucción del procedimiento. En el supuesto de que el órgano decisorio ejerza correctamente su función, sin limitarse sin más a asumir lo realizado en la instrucción, se puede hablar de que tal separación constituye una garantía para el imputado. Para ello, a mi modo de ver, debería reforzarse la exigencia de la motivación de la resolución como elemento causal fundamental de la resolución sancionadora, exigiéndose una valoración de la prueba practicada durante la fase de instrucción y no una simple remisión a lo dispuesto en la propuesta de resolución.

\section{Poner en conocimiento de la Administración los hechos y la responsabilidad de la infracción: las denuncias obligatorias y voluntarias}

El poner en conocimiento de la Administración los hechos y la responsabilidad de la infracción se realiza a través del documento conocido como denuncia. La denuncia no es ni más ni menos que la notitia criminis, es decir dar traslado de unos hechos a la Administración pública para que realice las actuaciones pertinentes. Esta denuncia puede ser realizada por un agente de la autoridad que tiene encomendadas estas funciones, en cuyo caso tendrá carácter obligatorio, o por cualquier ciudadano, en cuyo caso tendrá carácter voluntario. Ahora bien, a parte de una mera comunicación de unos hechos, el ordenamiento jurídico le ha atribuido otras funciones que si bien pueden considerarse complementarias no dejan de tener una importancia trascendental.

En primer lugar, "la denuncia formulada por los Agentes de la autoridad encargados del servicio de vigilancia del tráfico y notificada en el acto al denunciado, constituye el acto de iniciación del procedimiento sancionador, a todos los efectos" (art. 73.2 del Texto Articulado de la Ley de Tráfico)9. Ello significa que desde el mismo momento que se formula comienzan a contar el plazo máximo para resolver y notificar la resolución del procedimiento administrativo. También significa que empiezan también a contar los plazos para que la persona denunciada pueda formular alegaciones y proponer pruebas o para acogerse al pago reducido de la multa a través del reconocimiento de su responsabilidad. La diferencia en un caso y otro es significativa por cuanto el incumplimiento del plazo de resolver y notificar comporta la caducidad del procedimiento, mientras que la no realización de alegaciones o el no acogerse al pago reducido comporta sencillamente la pérdida de dicho trámite.

9 Nótese que se está refiriendo a Agentes de la Autoridad condición que no reúnen los meros vigilantes de las zonas de estacionamiento vigilado. En este sentido vid. la STSJ País Vasco (Sala de lo Contencioso-Administrativo, Sección $3^{\text {a }}$ ) núm. 615/2000 de 29 junio (RJCA 200o|2113): “[ ] el documento notificación de denuncia que se documenta en el expediente administrativo como único documento de formalización de las denuncias efectuadas contra el recurrente por los Controladores de Estacionamiento, no constituye un acto hábil de incoación del procedimiento sancionador." 
Se plantea en qué medida la denuncia formulada por los particulares puede comportar el inicio del procedimiento. En general, se viene considerando que los denunciantes con un mero interés de legalidad no son interesados en el procedimiento ${ }^{10} \mathrm{y}$, por tanto, que únicamente tienen derecho a que se le comunique la iniciación o no del procedimiento cuando la denuncia vaya acompañada de una solicitud de iniciación (art. 11.2 in fine del Reglamento de procedimiento para el ejercicio de la potestad sancionadora) . Cabría plantearse si, en determinados casos, el denunciante podría ser también un interesado en el procedimiento. Esta circunstancia podría plantearse, por ejemplo, cuando el denunciante fuera víctima de un accidente de circulación en el que el causante hubiera cometido una infracción administrativa.

En segundo lugar, el hecho que las denuncias de los Agentes de la autoridad comporten la iniciación del procedimiento faculta a éstos a la adopción de la medida provisional de inmovilización del vehículo. Esta medida provisional solamente puede adoptarse en los supuestos tasados previstos en el art. 84 del Texto Articulado de la Ley de Tráfico"1. La justificación reside fundamentalmente en el riesgo que constituye para la seguridad vial el que el vehículo en cuestión pueda seguir circulando.

En tercer lugar, en el caso que el denunciado no formule alegaciones ni abone el importe de la multa en el plazo de quince días naturales siguientes al de la notificación de la denuncia, ésta cuando tenga carácter obligatorio surtirá el efecto de acto resolutorio del procedimiento sancionador ${ }^{12}$. En este supuesto, la sanción podrá ejecutarse transcurridos treinta días naturales desde la notificación de la denuncia. Como vemos se trata de la máxima simplificación del procedimiento que queda reducido a un solo acto administrativo, la denuncia, que reúne al mismo tiempo la condición de acto iniciador y de acto resolutorio. Tal efecto requiere dos requisitos fundamentales para que ello se produzca: la inactividad del interesado no formulando alegación alguna y el transcurso del tiempo. A mi modo de ver, si bien tal situación

10 Por todos vid. M. Rebollo Puig: “Interesados y denunciantes en el procedimiento administrativo sancionador" en Poder Judicial 29, 1993, pp. 59-78.

11 Los supuestos que habilitan a adoptar la medida de inmovilización son los siguientes: “a) El vehículo carezca de autorización administrativa para circular, bien por no haberla obtenido o porque haya sido objeto de anulación, declarada su pérdida de vigencia; b) El vehículo presente deficiencias que constituyan un riesgo especialmente grave para la seguridad vial; c) El conductor o el pasajero no hagan uso del casco de protección, en los casos en que fuera obligatorio; d) Tenga lugar la negativa a efectuar las pruebas a que se refiere el artículo 12.2 y 3 o éstas arrojen un resultado positivo; e) El vehículo carezca de seguro obligatorio; f) Se observe un exceso en los tiempos de conducción o una minoración en los tiempos de descanso que sean superiores al 50 por ciento de los tiempos establecidos reglamentariamente, salvo que el conductor sea sustituido por otro; g) Se produzca una ocupación excesiva del vehículo que suponga aumentar en un 50 por ciento el número de plazas autorizadas, excluida la del conductor; h) El vehículo supere los niveles de gases, humos y ruido permitidos reglamentariamente según el tipo de vehículo; i) Existan indicios racionales que pongan de manifiesto la posible manipulación en los instrumentos de control; j) Se detecte que el vehículo está dotado de mecanismos o sistemas encaminados a eludir la vigilancia de los Agentes de Tráfico y de los medios de control a través de captación de imágenes."

12 Con todo, la aplicación del carácter de acto resolutorio a la denuncia será de aplicación únicamente cuando se trate de: a) Infracciones leves. b) Infracciones graves que no detraigan puntos. c) Infracciones graves y muy graves cuya notificación se efectuase en el acto de la denuncia. 
puede ser óptima desde una perspectiva de simplificación administrativa, parece más discutible desde un punto de vista de las garantías del ciudadano, reducir el procedimiento a un único acto administrativo que hace las veces de iniciación, instrucción y resolución, en la que la única valoración de los hechos y de la sanción procedente es realizada exclusivamente por el agente denunciante.

En cuarto lugar, "las denuncias formuladas por los Agentes de la Autoridad encargados de la vigilancia del tráfico darán fe, salvo prueba en contrario, de los hechos denunciados y de la identidad de quienes los hubieran cometido, así como, en su caso, de la notificación de la denuncia, sin perjuicio del deber de aquéllos de aportar todos los elementos probatorios que sean posibles sobre el hecho denunciado" (art. 75 del Texto Articulado de la Ley de Tráfico). Se trata de la denominada presunción de certeza o veracidad de las denuncias, actas de inspección y otros documentos administrativos, que examinaremos más adelante. Es decir que pueden ser considerados como medios de prueba para fundamentar la imposición de una sanción administrativa sin que ello suponga necesariamente una vulneración del derecho fundamental a la presunción de inocencia.

\section{Asegurar la eficacia de la sanción: Las medidas provisionales}

Hemos visto anteriormente como los Agentes de la autoridad podían adoptar la medida provisional de inmovilización del vehículo en supuestos tasados debido al riesgo que genera la circulación del vehículo (art. 84 del Texto Articulado). También se prevé la medida provisional de retirada y depósito del vehículo que puede acordar la Autoridad encargada de la gestión del tráfico (art. 85 del Texto Articulado) en los casos también legalmente establecidos ${ }^{13}$.

Los gastos ocasionados por la adopción de medidas provisionales son objeto de tratamiento específico tanto en el caso de la inmovilización como el de retirada y depósito del vehículo. La regla establecida es que dichos gastos serán de cargo del titular, del arrendatario o del conductor habitual según los casos. Las excepciones que se prevén son en caso de sustracción del vehículo u otras formas de utilización del vehículo en contra de la voluntad del titular, debidamente justificadas.

13 Dichos supuestos tasados son los siguientes: “a) Siempre que constituya peligro, cause graves perturbaciones a la circulación de vehículos o peatones o deteriore algún servicio o patrimonio público; b) En caso de accidente que impida continuar su marcha; c) Cuando, procediendo legalmente la inmovilización del vehículo, no hubiere lugar adecuado para practicarla sin obstaculizar la circulación de vehículos o personas; d) Cuando, inmovilizado un vehículo de acuerdo con lo dispuesto en el artículo 84, no cesasen las causas que motivaron la inmovilización; e) Cuando un vehículo permanezca estacionado en lugares habilitados por la autoridad municipal como zonas de aparcamiento reservado para el uso de personas con discapacidad sin colocar el distintivo que lo autoriza; f) Cuando un vehículo permanezca estacionado en los carriles o partes de las vías reservados exclusivamente para la circulación o para el servicio de determinados usuarios y en las zonas reservadas a la carga y descarga; g) Cuando un vehículo permanezca estacionado en lugares habilitados por la autoridad municipal como de estacionamiento con limitación horaria sin colocar el distintivo que lo autoriza, o cuando se rebase el triple del tiempo abonado conforme a lo establecido en la Ordenanza Municipal." 
La posibilidad de interponer recursos es otra de las cuestiones que pueden plantearse. La liquidación de los gastos que genere la adopción de medidas provisionales constituye un acto administrativo resolutorio que puede ser impugnado a través de los recursos administrativos ordinarios (alzada y reposición). En cambio, la adopción propiamente dicha de la medida provisional constituye un acto administrativo de trámite que, como regla general, no son susceptibles de una impugnación administrativa autónoma sino a través de la correspondiente resolución una vez finalizado el procedimiento administrativo. No obstante, se plantea en este caso si estamos ante un acto de trámite cualificado que, de acuerdo con el art. 107.1 de la LRJPAC, admiten una impugnación autónoma, como excepción a la regla general. Estos actos de trámite cualificados son los siguientes: si deciden directamente o indirectamente el fondo del asunto, determinan la imposibilidad de continuar el procedimiento, y producen indefensión o perjuicio irreparable a derechos e intereses legítimos. En la medida que estas medidas provisionales ocasionen indefensión ${ }^{14}$ o perjuicio irreparable a derechos e intereses legítimos cabrá su impugnación autónoma. Tal situación de perjuicio irreparable se produciría claramente, a mi juicio, en aquellos casos de inmovilización o depósito de vehículos que están directamente vinculados con el ejercicio de una actividad empresarial o profesional.

\section{Fijar la acusación: La relación entre el acuerdo de iniciación, la propuesta de resolución y la resolución}

Con carácter previo a la adopción de la resolución encontramos una serie de actos administrativos de trámite en los que se fija la acusación. Constituyen documentos acusatorios en virtud de los cuáles el imputado en el procedimiento sancionador puede articular su defensa. Entre los derechos del presunto responsable que reconoce el art. 135 de la LRJPAC encontramos el de "ser notificado de los hechos que se le imputen, de las infracciones que tales hechos puedan constituir y de las sanciones que, en su caso, se les pudiera imponer".

La función del acuerdo de iniciación o de la denuncia del Agente de la Autoridad que inicia el procedimiento, aparte de abrir formalmente las actuaciones, es la de garan-

14 En la STS (Sala de lo Contencioso-Administrativo, Sección $4^{\text {a }}$ ) de 12 noviembre 1997 (RJ 1997 8538 ) se distingue entre el acto de incoación de un procedimiento administrativo sancionador, que "no constituye otra cosa que una mera actuación de trámite, cuya naturaleza provisional la hace totalmente inadecuada para revestir el concepto de acto definitivo -y en consecuencia recurrible-“, y una medida provisional "adoptada implique una limitación de la conducta o los derechos del administrado, ha de evitarse la indefensión que proscribe el artículo 113 de la Ley antes citada, y resolver, en congruencia con su texto, que no solamente las resoluciones administrativas, sino cualesquiera actos de trámite que determinen la imposibilidad de continuar el procedimiento, u originen indefensión, son susceptibles de recurso contencioso, pese al carácter instrumental normalmente atribuible a tales remedios de carácter provisional”. Abundando en la impugnabilidad de estas medidas vid. M. Rebollo Puig: "Medidas provisionales en el procedimiento administrativo" en AA.VV: La protección jurídica del ciudadano: (procedimiento administrativo y garantía jurisdiccional): Estudios en homenaje al profesor Jesús González Pérez, Vol. 1, 1993 (Consideraciones generales: el procedimiento administrativo), pp. 659-710. 
tizar el derecho de defensa. Para ello, deben precisarse adecuadamente los hechos que se imputan al presunto responsable, así como informar de los derechos que asisten al ciudadano para que formule las alegaciones, aporte documentos y proponga las pruebas necesarias para su defensa.

En la propuesta de resolución se fijan los hechos que el instructor considera probados y propone sancionar al inculpado por la realización de una determinada sanción. Se trata de un momento decisivo porque abre la última vía de defensa antes que el órgano competente decida sobre el asunto y de por terminado el procedimiento administrativo sancionador. Ello ha llevado a comparar esta propuesta de resolución del procedimiento administrativo sancionador con el escrito de calificación definitiva en el proceso penal, mientras que el acuerdo de iniciación sería el escrito de imputación o inculpación ${ }^{15}$. Ello implica que el órgano resolutorio para poder agravar la sanción propuesta debe dar al imputado la posibilidad de defenderse, por lo que será necesaria su notificación, para que éste pueda discutir las sanciones propuestas así como su graduación.

El art. 105.c) de la Constitución establece que la ley regulará el procedimiento a través del cual deben producirse los actos administrativos, garantizando, cuando proceda, la audiencia del interesado. En el propio precepto constitucional se está reconociendo que no siempre es necesario dar audiencia al interesado. En este sentido lo reconoce la normativa general cuando el art. 84 de la LRJPAC establece que "se podrá prescindir del trámite de audiencia cuando no figuren en el procedimiento ni sean tenidos en cuenta en la resolución otros hechos ni otras alegaciones y pruebas que las aducidas por el interesado". Esta posibilidad es transformada en un mandato por el art. 81.4 del Texto Articulado de la Ley de Tráfico señalando que: "Únicamente se dará traslado de la propuesta al interesado, para que pueda formular nuevas alegaciones en el plazo de quince días naturales, si figuran en el procedimiento o se hubiesen tenido en cuenta en la resolución otros hechos u otras alegaciones y pruebas diferentes a las aducidas por el interesado."

\section{Identificar al responsable: el deber de colaboración de los ciudadanos con la Administración}

De acuerdo con el principio de responsabilidad, sólo pueden ser sancionadas por hechos constitutivos de infracción administrativa las personas físicas o jurídicas que resulten responsables, aunque sólo sea por simple inobservancia (art. 130.1 de la LRJPAC). Este principio se traduce en el procedimiento administrativo sancionador en la necesidad de determinar quién es la persona responsable. En algunas situaciones únicamente se puede constatar que la infracción se ha cometido mediante la utilización de un determinado vehículo, que resulta plenamente identificable, pero no así qué persona lo estaba conociendo en aquél momento.

15 Esta comparación ha sido realizada en la STS de 30 de marzo de 1989 (RJ 2.151|1989). 
El establecimiento de una presunción que atribuyera al propietario o arrendador del vehículo la comisión de la infracción administrativa sería contraria al derecho a la presunción de inocencia ${ }^{16}$. Ahora bien, la Ley fija un deber de colaboración en el art. 81.2 del Texto Articulado de la Ley de Tráfico para identificar "al conductor responsable de la infracción" "17 contra el que se iniciará el procedimiento sancionador, identificación que se efectuará por medios telemáticos si la notificación se hubiese efectuado a través de la Dirección Electrónica Vial. Se trata de una concreción en este ámbito del deber general de colaboración de los ciudadanos que establece el art. 39.2 de la LRJPAC cuando se señala que los interesados en un procedimiento que conozcan datos que permitan identificar a otros interesados que no hayan comparecido en él tienen el deber de proporcionárselos a la Administración actuante. Debe notarse que el deber de colaboración se dirige a identificar a la persona que estaba en el momento en que se formula la denuncia conduciendo el vehículo, no comporta necesariamente que se esté realizando la incriminación de esta persona, ya que ello le corresponderá a la Administración que es quien tiene la carga de la prueba. Cuando el propietario o arrendador del vehículo se niegue a identificarlo se le sancionará no por los hechos sobre los cuales se le requiere su colaboración, sino por una infracción autónoma de carácter muy grave como es la del "incumplimiento por el titular o el arrendatario del vehículo con el que se haya cometido la infracción de la obligación de identificar verazmente al conductor responsable de dicha infracción, cuando sean debidamente requeridos para ello en el plazo establecido" [art 65.5.j) del Texto Articulado de la Ley de Tráfico]. Procedimentalmente, en estos casos las actuaciones se dirigirán al propietario o arrendatario otorgándole un plazo de quince días para que proceda a la identificación del conductor.

\section{Acreditar o desvirtuar los hechos: el derecho a la prueba y a la presunción de inocencia}

El derecho a la prueba es un derecho de relevancia constitucional que es de aplicación a los procedimientos administrativos sancionadores ${ }^{18}$. Este derecho comporta

16 Sobre esta tensión con el derecho a la presunción de inocencia vid. J. Garberí Llobregat: “Presunción de inocencia versus deber de colaboración cívica con la administración sancionadora" en Poder Judicial 14, 1989, pp. 113-122.

17 Como se señaló en la STC 197/1995 de 21 diciembre: “[ ] ciertamente la redacción de la norma cuestionada no es técnicamente afortunada, ya que se refiere expresamente al deber del titular del vehículo "de identificar al conductor responsable de la infracción", como si aquél pudiera determinar tal responsabilidad o como si la responsabilidad hubiera sido ya declarada por la Administración con sólo incoar el expediente sancionador. Pero aun con esa defectuosa redacción, resulta evidente que, al titular del vehículo no le corresponde en modo alguno declarar la responsabilidad o culpabilidad del conductor supuestamente autor de la infracción, sino que tal declaración se efectuará, en su caso, por la Administración tras la conclusión del oportuno expediente sancionador, en cuya tramitación el conductor podrá alegar en su descargo y proponer la práctica de cuantas pruebas considere pertinentes. De modo que tampoco en este extremo debe reputarse inconstitucional el precepto dubitado [ ]."

18 Sobre el alcance de este derecho constitucional a los procedimientos administrativos sancionadores V. Aguado i Cudolà: “La prueba en el procedimiento administrativo sancionador” en Justicia adminis- 
que la denegación de pruebas debe realizarse de forma motivada en aquellos casos en que sean manifiestamente improcedentes ${ }^{19}$.

La utilización de pruebas técnicas, si bien puede dar un alto grado de fiabilidad en la constatación de determinados hechos como pueden ser el exceso de velocidad o la conducción bajo los efectos del alcohol, no puede predeterminar en cualquier caso la sanción administrativa. Ello debe compensarse con la oportunidad de que el ciudadano pueda a través de la fase probatoria cuestionar la fiabilidad de los dispositivos técnicos y de su utilización por los funcionarios encargados de la vigilancia del tráfico ${ }^{20}$.

Por lo que se refiere a la constatación de hechos a través de los Agentes de la Autoridad se recoge en el art. 75 del Texto Articulado de la Ley de Tráfico que establecen la presunción de certeza o veracidad y, por tanto, su valor probatorio como prueba documental de cargo en que fundamentar la sanción. Si las alegaciones formuladas aportasen datos nuevos o distintos de los constatados por el Agente denunciante, y siempre que se estime necesario por el instructor, se dará traslado de aquéllas al Agente para que informe en el plazo de quince días naturales. Este informe viene a ser la forma que tiene el Agente denunciante de ratificarse en los hechos ${ }^{21}$. Para de-

trativa. Revista de derecho administrativo, ISSN 1139-4951, N. ${ }^{\circ}$ Extra 1, 2001 (Ejemplar dedicado a: Infracciones, sanciones y procedimiento administrativo sancionador), pp. 93-114.

19 Vid. la STSJ País Vasco (Sala de lo Contencioso-Administrativo, Sección $3^{\text {a }}$ ) núm. 848/2000 de 5 octubre (RJCA 2001|195) “De conformidad con el artículo 12 del Real Decreto 320/1994, de 25 de febrero el recurrente alegó lo que estimó por conveniente así como propuso las pruebas más arriba consignadas. Sin embargo, el instructor del procedimiento, olvidando las más elementales garantías a adoptar para evitar la indefensión del administrado, no sólo no practicó prueba (salvo la remisión al interesado de un certificado de verificación periódica del cinemómetro), sino evitando resolver sobre la admisión o rechazo de las demás pruebas propuestas. Un somero examen de las diligencias propuestas por don Sergio Juan P. A. exige un mínimo pronunciamiento sobre su pertinencia por parte de la administración sancionadora pues reviste indudable relación con el fondo de los hechos y la prueba de cargo acerca de los mismos. Así, la aptitud de los agentes denunciantes para el manejo del cinemómetro utilizado, incluso la de su conocimiento acerca de las normas de circulación vial, necesariamente muestra la pertinencia de la prueba solicitada por el recurrente respecto de la capacitación de los agentes denunciantes para la utilización del aparato medidor."

20 Según la Sentencia del Juzgado de lo Contencioso-Administrativo núm. 1 de León de 3 marzo de 2003 (RJCA 2003157): “impone al agente denunciante la obligación de describir con precisión, en el boletín de denuncia o en el atestado de las diligencias que practique, el procedimiento seguido para efectuar la prueba o pruebas de detección alcohólica, haciendo constar los datos necesarios para la identificación del instrumento o instrumentos de detección empleados, cuyas características genéricas también detallará; así como consignar las advertencias hechas al interesado, especialmente la del derecho que le asiste a contrastar los resultados obtenidos en las pruebas de detección alcohólica por el aire espirado mediante análisis adecuados, acreditándose en las diligencias las pruebas o análisis practicados en el Centro sanitario al que fue trasladado el interesado."

21 Así, por ejemplo, el art. 37 de la Ley Orgánica 1/1992, de 21 de febrero, de protección de la seguridad ciudadana: "En los procedimientos sancionadores que se instruyan en las materias objeto de la presente Ley, las informaciones aportadas por los agentes de la autoridad que hubieren presenciado los hechos, previa ratificación en el caso de haber sido negados por los inculpados, constituirán base suficiente para adoptar la resolución que proceda, salvo prueba en contrario y sin perjuicio de que aquellos deban aportar al expediente todos los elementos probatorios disponibles". 
terminadas sentencias no resulta necesario dar traslado de este trámite al interesado aduciendo que no se produce indefensión ${ }^{22}$. A mi juicio, en cambio, resultaría necesario dicho traslado para asegurar una adecuada contradicción como resultado del derecho de defensa, ya que de otra forma estamos sobrevalorando estos documentos administrativos ${ }^{23}$.

\section{Tramitar el procedimiento administrativo sancionador en un tiempo razonable: la caducidad por incumplimiento de la obligación de resolver y notificar}

La Administración está obligada a dictar resolución expresa en todos los procedimientos y a notificarla cualquiera que sea su forma de iniciación (art. 42.1 de la LRJPAC). Al hablar de todos los procedimientos administrativos se incluyen tanto los iniciados a instancia de parte como los iniciados de oficio. Los procedimientos administrativos sancionadores son considerados como procedimientos de oficio por lo que en caso de incumplimiento de la obligación de resolver y notificar dentro del plazo máximo legalmente establecido comportará la aplicación de la caducidad del procedimiento (art. 44.2 de la LRJPAC).

De acuerdo con la normativa general (art. 42.2 de la LRJPAC), el plazo máximo para notificar la resolución expresa es el que fije la norma reguladora del procedimiento correspondiente. Este plazo no podrá exceder los seis meses salvo que una norma con rango de ley establezca uno de más largo o que lo prevea la normativa comunitaria europea. En el caso de los procedimientos administrativos sancionadores en materia de tráfico y seguridad vial el plazo máximo para resolver es de un año (92.3 del Texto Articulado de la Ley de Tráfico). En estos casos se establece un período de tiempo que duplica el plazo general de seis meses que habitualmente rige en los procedimientos administrativos sancionadores. Si bien cumple el requerimiento formal que este plazo superior a los seis meses esté previsto en una norma con rango

22 Vid. la STSJ de Castilla y León, Valladolid (Sala de lo Contencioso-Administrativo, Sección $1^{\mathrm{a}}$ ), sentencia núm. 1849/2005 de 6 septiembre (RJCA 20051712): "La indefensión que se alega por el demandante, al haberse vulnerado, en su opinión, el art. 85 de la Ley 30/1992, por no habérsele dado traslado en su domicilio del informe del Agente denunciante de 24 de abril de 1998, que consta en el expediente, de ratificación de la denuncia formulada, no puede prosperar, pues ese informe no es uno de los actos que requiere la "intervención" del interesado, que es a los que se refiere ese precepto, y así resulta de lo dispuesto en el art. 12.2 del RD 320/1994, de 25 de febrero, por el que se aprueba el Reglamento del Procedimiento Sancionador en materia de Tráfico, Circulación de Vehículos a Motor y Seguridad Vial, en el que se señala que de las alegaciones del denunciado, salvo que no aporten datos nuevos o distintos de los inicialmente constatados por el denunciante, "se dará traslado a éste, para que informe en el plazo máximo de quince días", pero sin especificar, para la emisión de ese informe, ninguna intervención del interesado. Además ha de señalarse que respecto de ese informe de ratificación de la denuncia, que consta en el expediente, como se ha dicho, ha podido el recurrente formular alegaciones en el proceso, por lo que carecería de sentido una hipotética nulidad de actuaciones para darle traslado del mismo, que ya ha conocido en este recurso y ha podido formular alegaciones frente a él, como ha hecho."

23 La tesis sobre la innecesariedad de dar traslado a este tipo de actuaciones ya fue sustentada por el Tribunal Constitucional en la STC 212/1990, de 20 de diciembre. Una crítica de esta jurisprudencia constitucional en V. Aguado i Cudolà: La presunción de certeza en el Derecho administrativo sancionador, Ed. Civitas, Madrid, 1994. 
de ley, no queda en cambio justificado el por qué de un plazo tan largo para resolver y notificar un procedimiento administrativo sancionador. Una explicación plausible del plazo de un año es el intentar evitar la caducidad del procedimiento atendiendo al carácter masivo que tienen las infracciones de tráfico y el posible colapso de las administraciones competentes. Ello, sin embargo, no parece una justificación razonable y atendible. Además puede destacarse como los plazos de la prescripción son notoriamente inferiores a los de la caducidad: tres meses para las infracciones leves y de seis meses para las infracciones graves y muy graves (art. 92.1 del Texto Articulado de la Ley de Tráfico). Por tanto, es mucho más probable que la infracción prescriba que el procedimiento caduque. Situación que resulta paradojal en cuanto la prescripción tiene efectos extintivos respecto a la responsabilidad administrativa sancionadora, mientras que la caducidad, en principio, solamente comporta la terminación del procedimiento.

Cabe señalar que al ser más cortos los plazos de prescripción difícilmente podrá iniciarse un nuevo procedimiento administrativo sancionador cuando se haya producido la caducidad. Hay que tener en cuenta que, de acuerdo con el art. 92.3 de la LRJPAC, la caducidad no producirá por sí sola la prescripción de las acciones del particular o de la Administración, pero los procedimientos caducados no interrumpirán el plazo de prescripción ${ }^{24}$.

Respecto al inicio del cómputo del plazo de resolver y notificar, debe destacarse que STS (Sala $3^{\text {a }}$ ) de 15 de noviembre de 2000 ha fijado doctrina legal en rela-

24 La posibilidad de iniciar un nuevo procedimiento administrativo sancionador cuando se ha producido la caducidad de procedimiento es una cuestión pacífica en la jurisprudencia del Tribunal Supremo, como demuestra la STS de 12 de junio de 2003 (RJ 2003/4602) que sienta doctrina legal en este tema. En cambio, los autores se muestran más divididos. Una exposición de cuáles son las diversas tendencias doctrinales puede encontrarse en J. Messeguer Yebra: "A vueltas con la caducidad en los procedimientos sancionadores (Comentario de urgencia a la Sentencia del Tribunal Supremo de 12 de junio de 2003)" en Revista Jurídica de Castilla y León núm. 1, septiembre 2003, pp. 213-222. Por una parte, hay algunos autores que consideran que es posible iniciar un nuevo procedimiento administrativo sancionador mientras no se produzca la prescripción de la infracción. En este sentido encontramos a J. Garberí Llobregat, V. Aguado i Cudolà, M. Gómez Puente, F. Sainz Moreno y R. Estévez Goytre. Por otra parte, encontramos otros autores que opinan que es imposible iniciar un nuevo procedimiento administrativo sancionador cuando se ha producido la caducidad del procedimiento, apoyándose en algunas sentencias minoritarias que han dictado algunos tribunales superiores de justicia. En esta línea se sitúan R. Caballero Sánchez y J. A. López Pellicer. Esta última posición si bien resulta más favorable al imputado en un procedimiento administrativo sancionador, no tiene apoyo desde un punto de vista legislativo, sino más bien al contrario, como se deduce del art. 92.3 de la LRJPAC (al cual se remite el art. 44.2). Los efectos de la caducidad únicamente se proyectan sobre el procedimiento administrativo, pero no sobre la responsabilidad administrativa sancionadora que solamente se extingue por unas causas determinadas: cumplimiento de la sanción, muerte del infractor, disolución de la persona jurídica y prescripción. Por tanto, mientras no se extingue la responsabilidad administrativa sancionadora, la Administración puede ejercer sus potestades administrativas sancionadoras. Entenderlo de otra forma denota una confusión entre dos instituciones, prescripción y caducidad, que tienen un régimen jurídico distinto y responden a un fundamento jurídico distinto. La caducidad es una de las consecuencias jurídicas que comporta el incumplimiento de la obligación de resolver y notificar un procedimiento administrativo. La prescripción es, en cambio, la extinción de la responsabilidad ad78 jurídica al ciudadano. 
ción con el artículo 16 del Reglamento de Procedimiento Sancionador en Materia de Tráfico, Circulación de Vehículos a Motor y Seguridad Vial, aprobado por Real Decreto 320/1994, de 25 de febrero. De acuerdo con la normativa general de la LRJPAC el plazo de iniciación se inicia en los procedimientos iniciados de oficio, desde la fecha del acuerdo de iniciación. En el caso de los procedimientos sancionadores en materia de tráfico y seguridad vial se planteó si dicho plazo se iniciaba con la denuncia cuando ésta no ha podido ser notificada en el acto de la comisión de la infracción. El Tribunal Supremo consideró que a estos efectos el inicio del cómputo no puede efectuarse a partir de la fecha de la denuncia por el agente, sino desde la fecha de incoación por órgano competente una vez conocida la identidad del infractor.

\section{Agilizar el procedimiento: Procedimiento ordinario y procedimiento abreviado}

Entre las especialidades del procedimiento sancionador de tráfico, está el propio carácter de la infracción cometida. Esta posibilidad se traduce en que el imputado pueda acogerse a un procedimiento sancionador abreviado en el que se renuncia a formular alegaciones a cambio de beneficiarse de un pago de la sanción en cuantía reducida. Por tanto, el Texto Articulado de la Ley de Tráfico distingue esencialmente entre un procedimiento sancionador ordinario y el procedimiento sancionador abreviado (arts. 79, 80 y 81). Mientras que el primero se caracteriza por su carácter contradictorio en cuanto el imputado ejerce su derecho a la defensa a través de la formulación de alegaciones y, en su caso, la propuesta de pruebas, en el segundo se caracteriza por su carácter simplificado en cuanto se le considera que ha desistido de dichos trámites, dejando expedita la vía contencioso-administrativa. Debe remarcarse que el hecho que el interesado se acoja al pago en cuantía reducida no supone una renuncia a su derecho a la tutela judicial efectiva, en cuanto se trata de un derecho fundamental indisponible. Se trata simplemente de una forma de evitar la tramitación innecesaria de procedimientos sancionadores en aquéllos casos en que la decisión pueda resultar bastante clara a cambio de que el imputado se acoja a un beneficio económico como es la reducción del pago ${ }^{25}$.

25 La constitucionalidad de procedimientos abreviados por pago en cuantía reducida fue resuelta por la STC 76/1990, de 26 de abril (BOE de 30 de mayo de 1990) (Ley de modificación parcial de la Ley General Tributaria) (Ponente: D. Jesús Leguina Villa) en los siguientes términos: “[...] el art. 89.2 prescribe la renuncia al ejercicio de toda acción de impugnación para poder solicitar la condonación graciable de la sanción tributaria; con ello el legislador pretende agilizar y flexibilizar el cobro de las deudas tributarias, debiendo entenderse que la condonación afecta sólo a la sanción y no al resto de la deuda tributaria. Pero, desde la perspectiva del sujeto responsable, es claro que esta abstención en el ejercicio de impugnaciones no supone una renuncia, al derecho a la tutela judicial efectiva, lo que sería en sí mismo inconstitucional, dado el carácter irrenunciable e indisponible de este derecho fundamental, sino simplemente al uso de tal derecho y de las acciones en que se manifiesta por un período de tiempo y en relación con un acto administrativo concreto. Y la razón de tal renuncia es similar a la del supuesto anteriormente examinado, pues aquí se trata también de obtener un beneficio al que no se tiene derecho alguno - la condonación en forma graciable de la sanción - a cuyo fin es preciso satisfacer la carga de la previa renuncia a impugnar la liquidación practicada. En la medida en que tal sacrificio no resulta desproporcionado, se adopta libremente por el interesado y con el mismo se obtiene un beneficio graciable, que es el que mejor conviene a los intereses 
Lo que no puede realizarse es condicionar este beneficio de pago reducido a que el interesado reconozca los hechos por cuanto ello iría en contra del derecho a no confesarse culpable que como garantía recoge el art. 24.2 de la Constitución ${ }^{26}$. Esta cuestión ha sido resulta, precisamente, en el ámbito del tráfico y seguridad vial, en la STS Tribunal Supremo (Sala de lo Contencioso-Administrativo, Sección $5^{\text {a }}$ ) de 27 octubre 2004 (RJ 2005/14). En esta sentencia se declaró nulo de pleno derecho el apartado 2, párrafo segundo, del artículo 12 del Reglamento de procedimiento sancionador en materia de tráfico, circulación de vehículos a motor y seguridad vial según modificación operada por Real Decreto 318/2003, de 14 de marzo ${ }^{27}$. El razonamiento que se basa para declarar la nulidad de este precepto es que: "en los supuestos de reacción del denunciado, autoriza a imponer y exigir a éste el importe íntegro de la multa que proceda, ya que sólo tiene en cuenta el pago anticipado cuando el procedimiento termine por no haberse formulado alegaciones, y, en el caso de impugnarse la resolución sancionatoria, se desvincula la decisión del recurso del hecho de haberse pagado anticipadamente, con lo que el precepto reglamentario impugnado modifica e innova los preceptos legales, al suprimir el derecho a la reducción de la multa procedente cuando el denunciado no se conforma con ella." En la actualidad, el Texto Articulado de la Ley de Tráfico, establece que el pago anticipado en cuantía reducida supone la terminación del procedimiento, sin necesidad de dictar resolución expresa [art. 80.c)], así como el agotamiento de la vía administrativa siendo recurrible únicamente ante el orden jurisdiccional contencioso-administrativo [art. 80.d)]. Por tanto, el que una persona se acoja al pago en cuantía reducida no excluye que no pueda mostrar su disconformidad con la sanción administrativa a través del recurso contencioso-administrativo correspondiente sin que por ello deba privarse del mencionado beneficio. Entenderlo de otra forma sería como resucitar el antiguo privilegio del solve et repete que es contrario frontalmente al derecho fundamental a la tutela judicial efectiva.

del peticionario de la condonación, no hay transgresión de derecho fundamental alguno. Este Tribunal ha declarado que, si bien los derechos fundamentales son permanentes e imprescriptibles, ello es perfectamente compatible con el establecimiento de límites temporales dentro del ordenamiento para el ejercicio de las correspondientes acciones (STC 7/1983, fundamento jurídico $3^{\circ}$ ). Si la imprescriptibilidad de los derechos fundamentales no es un obstáculo al carácter temporal de las acciones para su defensa, la irrenunciabilidad de tales derechos no impide tampoco la voluntaria y transitoria renuncia al ejercicio de las acciones en pos de unos beneficios graciables cuyo eventual logro es para el interesado más ventajoso que el que pudiera resultar de aquel ejercicio. En resumen, el art. 89.2 de la LGT no impide acceder a los Tribunales de Justicia a los contribuyentes infractores, sino que sólo condiciona la obtención de un beneficio a la no impugnación del acto administrativo correspondiente. La libertad del contribuyente para elegir entre una u otra vía, según mejor convenga a sus intereses, queda así salvaguardada y, por ello, no existe vulneración alguna del artículo 24.1 de la Constitución."

26 Vid. B. Lozano Cutanda: La extinción de las sanciones administrativas y tributarias, Ed. Marcial Pons, Madrid, 1990.

27 Este artículo decía lo siguiente: “La resolución que se dicte lo será por el importe total de la multa que proceda imponer y tendrá en cuenta el pago anticipado que se hubiera efectuado con anterioridad a los efectos previstos en el artículo 77.2 del texto articulado de la Ley sobre Tráfico, Circulación de Vehículos a Motor y Seguridad Vial, en cuanto se refiere a la terminación del procedimiento. En todo caso, 80 se formule, cuya resolución no quedará vinculada por el pago anticipadamente realizado". 


\section{Evitar el incumplimiento de la sanción: el procedimiento de ejecución}

La jurisprudencia constitucional considera que el derecho a la tutela judicial efectiva "se satisface facilitando que la ejecución pueda ser sometida a la decisión de un Tribunal y que éste, con la información y contradicción que resulte menester, resuelva sobre la suspensión" ${ }^{28}$. Por tanto, no se requiere cómo en el ámbito penal que exista una sentencia firme, en estricta aplicación del derecho fundamental a la presunción de inocencia. Ahora bien, tampoco es suficiente con que se haya dictado la sanción administrativa, sino que se requiere que la ejecución pueda ser sometida a la decisión de un órgano jurisdiccional. El legislador ha identificado este momento cuando el acto administrativo pone fin a la vía administrativa (art. 138.3 de la LRJPAC).

Como hemos visto anteriormente, la legislación específica en materia de tráfico establece que las sanciones administrativas ponen fin a la vía administrativa. Con ello se persigue su ejecutividad inmediata (81.5 del Texto Articulado de la Ley de Tráfico). La única excepción se encuentra en las sanciones de suspensión de las autorizaciones al prever su cumplimiento un mes después de que la sanción haya adquirido firmeza en vía administrativa (art. 89 del Texto Articulado de la Ley de Tráfico).

La justificación de la inmediata ejecutividad de las sanciones de tráfico se realiza en base a su carácter especial, tal y como hemos visto al inicio de este trabajo. Esta justificación es similar a la acontecida con la legislación de extranjería, cuya compatibilidad con la Constitución ha sido resuelta recientemente por la STC 259/2007, de 19 de diciembre. Este régimen de inmediata ejecutividad fue cuestionado por cuanto parecía querer excepcionar del régimen general sobre la ejecutividad de los actos administrativos a la orden de expulsión adoptada en el seno del procedimiento preferente, remitiéndose a lo dispuesto en esta Ley para la tramitación de expedientes con carácter preferente. A pesar de ello, el Tribunal Constitucional considera que ello es ajustado a la Constitución por cuanto no se está modificando el régimen general de ejecutividad en cuanto una vez que pone fin a la vía administrativa se posibilita que se solicite el oportuno control jurisdiccional sobre la medida.

La posibilidad de que se adopten medidas cautelares, en especial la suspensión de la sanción, constituye una garantía importante para el ciudadano. La doctrina general que viene utilizando la jurisprudencia del Tribunal Supremo para conceder la suspensión de la sanción de tráfico requiere, en primer lugar, que nos encontremos ante una sanción de privación del permiso de conducir y, en segundo lugar, que recaiga sobre un profesional de la conducción. En estos casos en que la sanción puede provocar una extinción, o cuando menos una suspensión, de la relación jurídica laboral se suele conceder la medida cautelar ${ }^{29}$.

28 Vid. las SSTC 66/1984, de 6 de junio; 76/1992, de 14 de mayo; 148/1993, de 29 de abril; 341/1993, de 18 de noviembre; 78/1996, de 20 de mayo; AATC 265/1985, de 24 de abril; 458/1988, de 18 de abril; 116/1995, de 4 de abril; 95/2000, de 30 de marzo.

29 Vid. la Sentencia de la Audiencia Nacional (Sala de lo Contencioso-Administrativo, Sección $1^{\mathrm{a}}$ ), sentencia de 16 febrero 2001 (RJCA 2001|869) donde se resume la doctrina del Tribunal Supremo al respec- 


\section{CONCLUSIONES: EL DEBIDO EQUILIBRIO ENTRE ESPECIALIDADES Y GARANTÍAS COMUNES}

La Ley 18/2009, de 23 de noviembre, ha introducido novedades significativas en el procedimiento sancionador de tráfico, en búsqueda de una mayor simplificación administrativa y de una mayor eficacia de la Administración. Para ello ha acentuado el carácter singular de este procedimiento respecto a la regulación general de la LRJPAC de la que se remarca, con toda rotundidad, su carácter supletorio, tal y como ha acontecido con otros procedimientos tales como en materia tributaria, seguridad social y desempleo, infracciones en el orden social y liquidación de cuotas de la seguridad social, disciplinarios, así como ante misiones diplomáticas y oficinas consulares. Por tanto, las garantías comunes que establece la legislación general de procedimiento administrativo, únicamente serán de aplicación en ausencia de regulación específica de la legislación sectorial.

Las características propias de las sanciones de tráfico, especialmente su carácter masivo y su carácter fugaz e instantáneo, justifican la adopción de determinadas especialidades procedimentales, como pueden ser la terminación anticipada del procedimiento a través de la reducción de la cuantía de la sanción y determinadas medidas destinadas a agilizar el procedimiento o administrativo y la ejemplaridad de las sanciones que puedan imponerse. Dichas especialidades no deberían suponer, sin embargo, una disminución o limitación de las garantías comunes de los ciudadanos ante las Administraciones públicas, sino que debe irse a un equilibrio que compatibilice las especialidades con las garantías.

Recibido: 12 de julio de 2010

Aceptado: 6 de septiembre de 2010

to. Así señala: “Dentro de esta línea de razonamiento, el TS ha entendido, en alguna ocasión, que procede la suspensión cuando la suspensión del permiso recaiga sobre un profesional de la conducción "ATS de 22 de julio de 1995 (RJ 1995, 6274)”. En esta línea, la STS de 13 de diciembre de 1996 (RJ 1996, 8856) razona que la privación del permiso de conducir, no es un perjuicio irreparable: "salvo que concurran especiales circunstancias que así lo determinen, como podría ser el que la conducción de los vehículos a motor constituyese la actividad profesional del recurrente". En el caso de autos, de las expresiones del recurrente (habla de despido disciplinario y salario), se infiere que está vinculado por una relación laboral, lo que admite el señor Abogado del Estado al contestar el recurso. Por lo que sin entrar a discutir sobre si la ejecución de la resolución administrativa de suspensión del permiso de conducir por un mes, podría derivar en su despido, es lo cierto que la doctrina laboral, por todas la STCT de 7 de mayo de 1986 ( RTCT 1986, 3123) , entiende que una privación temporal del permiso de conducir por escaso tiempo podría dar lugar a una suspensión temporal de la relación del trabajo, antes de acudir a la causa extintiva del art. 52.a) del ET ( RCL 1980, 607 y ApNDL 3006), que permite la extinción del contrato de trabajo por ineptitud del trabajador sobrevenida con posterioridad a su colocación efectiva en la empresa; y evidentemente la pérdida de la capacidad de conducir por quien es contratado como conductor puede ser subsumida en dicho tipo. Lo anterior implica que, por lo tanto, la ejecución de la sanción implicaría como mínimo la suspensión de la relación laboral por un mes, y por lo tanto como consecuencia del sinalagma propio de la relación laboral, la no prestación de trabajo y la no percepción de salario. Lo que genera una grave lesión de los intereses 82 de quien tiene como "modus vivendi" la conducción, no generándose una lesión tan grave para el interés público, por diferir la ejecución a la, en su caso, confirmación de la resolución." 